\title{
Sistem Informasi Berbasis Mobile Benda-BendaTradisional Pada Museum Balanga Palangkaraya
}

\author{
M. Haris Qamaruzzaman \\ Ilmu Komputer Universitas Muhammadiyah Palangkaraya \\ Alamat : Jl. RTA. Milono Km. 1,5 Palangkaraya, Kalimantan Tengah \\ E-mail : harisqamaruzzaman@yahoo.co.id
}

\begin{abstract}
ABSTRAK
Di dalam era globalisasi ini proses penyebaran informasi dapat melalui berbagai media salah satunya dengan media internet, karena internet merupakan teknologi sarana penyedia informasi yang setiap saat digunakan oleh masyarakat pada saat ini dan memperluas penyebaran informai tentang koleksi Museum Balanga Kota PalangkaRaya. Penelitian ini bertujuan untuk pembangunan sistem informasi berbasis mobile sebagai solusi dari pengolahan data baik dari segi penyimpanan maupun pelaporan yang dapat membantu sebagai media layanan informasi bagi masyarakat luas yang membutuhkan informasi pengenalan benda-benda peninggalan sejarah (etnografi) Budaya Suku Dayak yang ada di Museum Balanga palangkaraya menjadi lebih efektif dan efisien serta menjadi solusi bagi sistem yang berjalan saat ini,dalam melakukan kegiatan promosi masih menggunakan media promosi melalui buku, brosur, leaflet maupun dalam bentuk iklan di koran yang dirasakan terlalu banyak biaya yang dikeluarkan untuk kegiatan promosi tersebut. Perancangan sistem untuk alur sistem baik yang sedang berjalan maupun yang dibangun menggunakan UML serta untuk tampilan interface menggunakan software Balsamiq Mockups. Pengembangan sistem dilakukan menggunakan waterfall sebagai salah satu metode untuk membangun sistem secara cepat. Implementasi aplikasi menggunakan mobile dilakukan pengujian mengunakan black-box dan hasilnya sesuai harapan antara sistem yang dibangun dan yang diujikan.
\end{abstract}

Kata Kunci : Sistem Informasi, Mobile, Benda-benda tradisional, Waterfall

\section{ABSTRACK}

In this era of globalization the process of information dissemination through various media can be one with the internet, because the internet is an information technology provider means any time used by the community at the moment and extend the spread of the informai Balanga City Museum collection of PalangkaRaya. This research aims at the development of mobile-based information system as the solution of data processing or storage, both in terms of reporting which can help as a media information service for people who need information Introduction to historical heritage objects (Ethnography) of Dayak Culture that exists in the Museum Balanga palangkaraya become more effective and efficient as well as being a solution for systems that are running currently, in conducting promotional activities are still using media promotion through books, brochures, leaflets or in the form of an ad in the newspaper that felt too much of the costs incurred for promotional activities. The design of the system for the flow of good systems that are running or built using UML as well as for the look of the interface using Balsamiq Mockups. System development is done using the waterfall as one method to build the system quickly. Implementation of applications using mobile testing conducted using black-box and the results match expectations between systems that are built and fully tested.

Keywords : Information systems, Mobile, traditional objects, Waterfall

\section{PENDahuluan}

Di dalam era globalisasi ini proses penyebaran informasi dapat melalui berbagai media salah satunya dengan media internet, karena internet merupakan teknologi sarana penyedia informasi yang setiap saat digunakan oleh masyarakat pada saat ini dan memperluas penyebaran informai 
tentang koleksi Museum Balanga Kota PalangkaRaya.

Permasalahan yang dihadapi Museum Balanga saat ini adalah dalam melakukan kegiatan promosi masih menggunakan media promosi melalui buku, brosur, leaflet maupun dalam bentuk iklan di koran yang dirasakan terlalu banyak biaya yang dikeluarkan untuk kegiatan promosi tersebut sehingga kurangnya efisiensi dalam mencakup ketepatan maupun perluasan penyebaran informasi.

Solusi strategis untuk mengembangkan pengetahuan di Museum Balanga Kota Palangka Raya yaitu, dijadikan tempat pengumpulan cagar budaya, pelestarian, penelitian serta buktibukti sejarah dan menjadi tempat pendidikan, pengkajian, dan menjadi tempat rekreasi. Oleh karena itu salah satu usaha yang dapat dilakukan pengurus Museum Balanga adalah memberikan edukasi kepada pengunjung agar dapat terlibat dalam pelestarian benda-benda tradisional.

\section{TINJAUAN PUSTAKA}

2.1 Penelitian yang dilakukan oleh Trsinawati (2013) yang berjudul Pembuatan Sistem Informasi Bangunan Cagar Budaya Berbasis Web GIS (Studi Kasus di Koya Surabaya). Tujuan dalam penelitian ini adalah membuat aplikasi webGIS berupa sistem informasi bangunan cagar budaya Kota Surabaya yang informatif beserta solusi jalur alternatif sehingga dapat digunakan sebagai salah satu media penunjang tujuan wisata cagar budaya (heritage) di Kota Surabaya. Penelitian hanya berfokus pada objek yang ada diSurabaya dan aplikasi yang dikembangkan belum menggunakan web mobile.

2.2 Penelitian yang dilakukan Yudiantika (2013) yang berjudul Implementasi Augmented Reality Di Museum: Studi Awal Perancangan Aplikasi Edukasi Untuk Pengunjung Museum berfokus pada teknologi yang diterapkan dalam suatu museum dan menggunakan Augmented Reality (AR). AR. dikenal sebagai teknologi interaktif yang mampu memproyeksikan objek maya ke dalam objek nyata secara real time. Aplikasi AR yang diujicobakan dalam penelitian ini terdiri dari dua jenis, yaitu AR Desktop dan AR Mobile. Pengujian dilakukan dengan melakukan studi aplikasi dan studi pengguna. Pengunjung diminta untuk menggunakan beberapa aplikasi AR yang disediakan. Hasil penelitian tidak berbasis web dan aplikasi diletakkan dalam museum sehingga aplikasi hanya diakses di lokasi museum saja.

2.3 Dalam penelitian yang berjudul Sistem Pendukung Keputusan Revitalisasi Terhadap Bangunan dan Kawasan Cagar Budaya Kota Bandung Prabowo (2013), maksud dan tujuan dari dari penelitian ini adalah untuk menerapkan sistem pendukung keputusan revitalisasi terhadap bangunan dan kawasan cagar budaya Kota Bandung di DISBUDPAR Kota Bandung. Penelitian lebih ditekankan pada sistem yang digunakan untuk pendataan administrasi dan tidak untuk digunakan secara umum.

\section{METODE PENELITIAN}

Penelitian ini menggunakan metode pengembangan perangkat lunak System Development Life Cycle (SDLC) dengan pendekatan pengembangan model air terjun (waterfall) sebagaimana pada gambar berikut :

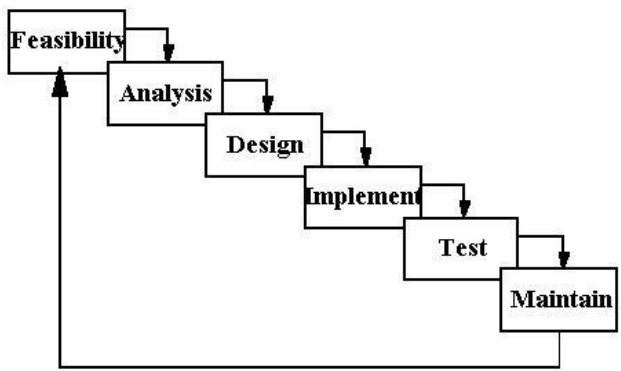

Gambar 1. Kerangka Kerja Pengembangan Sistem Informasi $(S D L C)$

Bahasa pemrograman yang digunakan yaitu $P h p$ dengan MySQL Server sebagai databasenya.

\section{HASIL DAN PEMBAHASAN 4.1 PERANCANGAN SISTEM}

\subsubsection{Use Case Diagram}

Dalam Use Case ini digambarkan interaksi user dengan Website Museum Balanga. Berikut penjelasan tiap case diatas.

1) Pada case ini Pengunjung akan menerima informasi berupa kumpulan benda-benda etnografi daerah khas dayak

2) Pada Case ini pengunjung akan menerima informasi kegiatan dan lainnya seputar Museum Balanga.

3) Pada case ini administrator mempunyai hak akses penuh terhadap sistem. Tahapan 
pertama administrator melakukan pengelolaan kumpulan benda etnografi, kemudian tahapan kedua administrator melakukan pengelolaan galeri, selanjutnya pada tahapan ketiga administrator melakukan pengelolaan profil informasi seputar Museum Balanga serta Pada Tahapan keempat administrator melakukan pengelolaan pengumuman, tahapan selanjutnya pengelolaan kritik dan saran dan pengelolaan kontak.

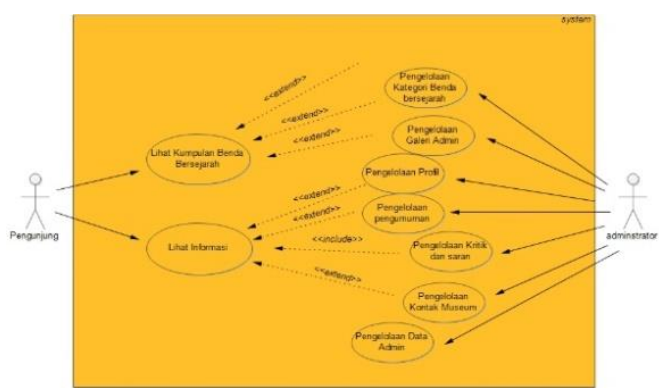

Gambar 2. Use Case Diagram

\subsubsection{Class Diagram}

Class Diagram adalah suatu diagram yang memperlihatkan atau menampilkan struktur dari sebuah sistem,sistem tersebut akan menampilkan sistem kelas dan relasi antar kelasnya. Berikut ini adalah class diagram pada sistem yang akan dibuat :

\section{Gambar 3. Class Diagram}

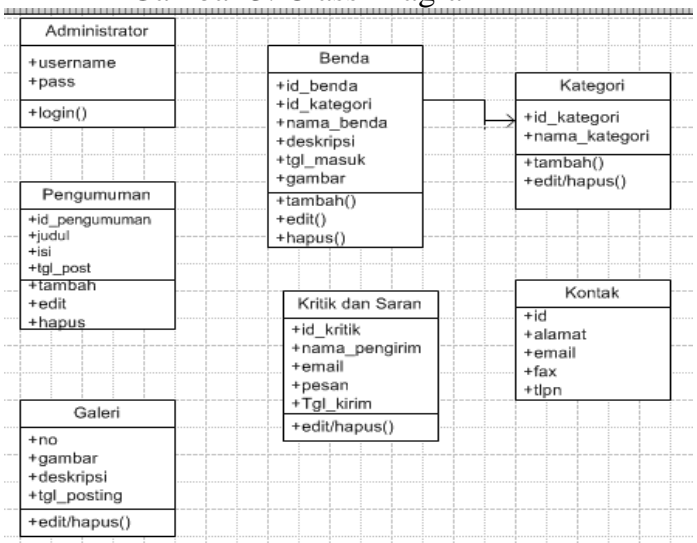

\subsection{ANTARMUKA SISTEM}

Antarmuka sistem yang dihasilkan terdiri dari 2 (dua), yaitu :

4.2.1 Antarmuka untuk User atau Pengunjung Pada halaman utama website ini, Pengunjung dapat memilih dan mengakses pilihan menumenu yang telah disediakan pada website Museum Balanga seperti profil museum balanga, koleksi etnografi, bantuan, tentang website dan tombol keluar.

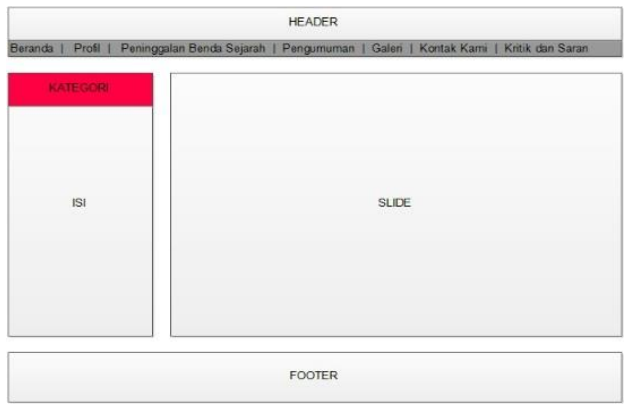

Gambar 4. Antarmuka Utama User

\subsubsection{Antarmuka Halaman Utama Administrator}

Halaman ini merupakan tampilan halaman utama administrator yang digunakan sebagai halaman untuk mengelola data-data dan informasi pada sistem yang nantinya akan ditampilkan pada halaman utama user. Halaman login merupakan halaman yang digunakan sebagai pintu gerbang bagi seorang administrator website sebelum masuk ke sistem untuk mengelola seluruh data-data pada sistem

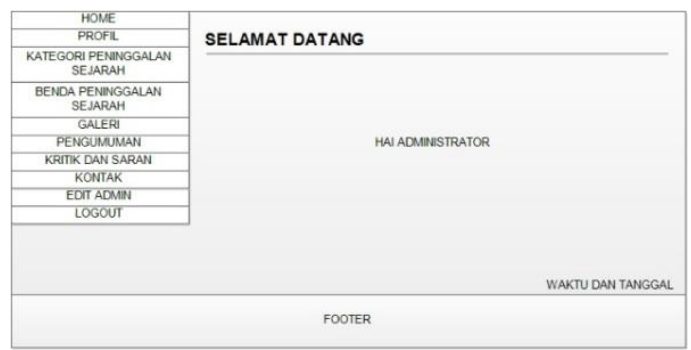

Gambar 4. Antarmuka Halaman admin

Pada menu halaman admin ini terdapat beberapa sub menu, yaitu :

1) Kelola data kategori digunakan untuk mengelola data kategori peninggalan sejarah, diantaranya yaitu menambah data, mengubah data dan menghapus data.

2) Kelola benda peninggalan sejarah untuk mengelola data untuk penginputan data-data detail profil benda yang akan disimpan.

3) Kelola data galeri digunakan untuk mengelola data galeri diantaranya yaitu menambah data, mengubah data dan menghapus data.

4) Kelola data pengumuman digunakan untuk mengelola data pengumuman, diantaranya yaitu menambah data, mengubah data dan menghapus data informasi. 
5) Kelola data kritik dan saran digunakan untuk mengelola data kritik dan saran, diantaranya yaitu mengubah data dan menghapus data.

6) Kelola data kontak digunakan untuk mengelola data kontak, diantaranya yaitu menambah data, mengubah data dan menghapus data.

7) Kelola data edit admin digunakan untuk mengelola data admin, diantaranya yaitu menambah data, mengubah data dan menghapus data.

\subsection{PENGUJIAN SISTEM}

Dalam tahapan proses pengujian pada sistem ini, penulis menggunakan metode "black box testing". Black box testing adalah suatu metode atau cara pengujian yang dilakukan untuk antar muka perangkat lunak dimana pada metode ini melakukan pengujian dengan memfokuskan hanya berdasarkan kebutuhan fungsional pada program dengan menggunakan data uji berupa sebuah data masukan yang akan diuji dengan tujuan untuk mengetahui apakah program sudah dapat berjalan sesuai dengan harapan yang dibutuhkan:

\subsubsection{Pengujian Client untuk User}

Hasil pengujiannya dapat dilihat pada tabel berikut :

Tabel 1. Hasil Pengujian Client

\begin{tabular}{|l|l|l|c|}
\hline No & \multicolumn{1}{|c|}{ Kelas Uji } & \multicolumn{1}{c|}{ Butir Uji } & $\begin{array}{c}\text { Jenis } \\
\text { Pengujian }\end{array}$ \\
\hline 1. & $\begin{array}{l}\text { Pengujian Lihat } \\
\text { Koleksi Kumpulan } \\
\text { Benda }\end{array}$ & $\begin{array}{l}\text { Proses Lihat Data } \\
\text { Koleksi Kumpulan } \\
\text { Benda }\end{array}$ & Black-Box \\
\hline 2. & $\begin{array}{l}\text { Pengujian Lihat } \\
\text { Informasi }\end{array}$ & $\begin{array}{l}\text { Proses Lihat Data } \\
\text { Informasi }\end{array}$ & Black-Box \\
\hline
\end{tabular}

4.3.2 Pengujian Sistem Server

Hasil pengujiannya dapat dilihat pada tabel berikut :

Tabel 2. Hasil pengujian Sistem Server

\begin{tabular}{|l|l|l|c|}
\hline No & \multicolumn{1}{|c|}{ Kelas Uji } & \multicolumn{1}{|c|}{ Butir Uji } & $\begin{array}{c}\text { Jenis } \\
\text { Pengujian }\end{array}$ \\
\hline 1. & $\begin{array}{l}\text { Pengujian login } \\
\text { administrator }\end{array}$ & $\begin{array}{l}\text { Login untuk } \\
\text { masuk ke halaman } \\
\text { administrator }\end{array}$ & Black-Box \\
\hline 2. & $\begin{array}{l}\text { Pengujian untuk } \\
\text { pengisian } \\
\text { pengelolaan data } \\
\text { kategori }\end{array}$ & Input data kategori & Black-Box \\
\hline 3. & $\begin{array}{l}\text { Pengujian untuk } \\
\text { pengisian } \\
\text { pengelolaan data } \\
\text { Benda }\end{array}$ & Input data Benda & Black-Box \\
\hline 4. & $\begin{array}{l}\text { Pengujian untuk } \\
\text { pengisian } \\
\text { pengelolaan data } \\
\text { galeri }\end{array}$ & Input data galeri & Black-Box \\
\hline 5. & $\begin{array}{l}\text { Pengujian untuk } \\
\text { pengisian } \\
\text { pengelolaan data } \\
\text { pengumuman }\end{array}$ & $\begin{array}{l}\text { Input data } \\
\text { pengumuman }\end{array}$ & Black-Box \\
\hline 6 & $\begin{array}{l}\text { Pengujian untuk } \\
\text { pengisian } \\
\text { pengelolaan data } \\
\text { kritik dan saran }\end{array}$ & $\begin{array}{l}\text { Input data kritik } \\
\text { dan saran }\end{array}$ & Black-Box \\
\hline 7. & $\begin{array}{l}\text { Pengujian untuk } \\
\text { pengisian } \\
\text { pengelolaan data } \\
\text { admin }\end{array}$ & $\begin{array}{l}\text { Input data admin } \\
\text { Black-Box } \\
/\end{array}$ \\
\hline
\end{tabular}

\section{KESIMPULAN}

5.1 Telah dapat dirancang dan dibangun Sistem Informasi Berbasis Mobile Benda - Benda Tradisional Pada Meseum Balanga Palangkaraya.

5.2 Berdasarkan hasil pengujian terhadap keseluruhan sistem diperoleh hasil yang sesuai dengan butir pengujian yang telah ditetapkan.

\section{ACUAN REFERENSI}

Prabowo, S. D. 2013. Sistem Pendukung Keputusan Revitalisasi Terhadap Bangunan dan Kawasan Cagar Budaya Kota Bandung di Disbudpar Kota Bandung. Jurnal Ilmiah Komputer dan Informatika (KOMPUTA) Vol. 2, No. 2, Oktober 2013, ISSN : 20899033, 27-33

Trsinawati, A. R. 2013. Pembuatan Sistem Informasi Bangunan Cagar Budaya Berbasis WebGIS (Studi Kasus di Kota Surabaya).Surabaya: Skripsi, Prodi Teknik Geomatika, Institut Teknologi Sepuluh Nopember Surabaya.

2012 : 1-7. ISSN : 2252-4908. Semarang : Politeknik Negeri Semarang.

Pressman, R. S., dan Maxim, B. R. 2013. Software Engineering: A Practitioner's 
M. Haris Qamaruzzaman. Sistem Informasi Berbasis Mobile Benda-BendaTradisional

Approach (8th ed.). New York: McGrawHill

Yudiantika, A. R. (2013)Suryo Guritno, Sudaryono, Implementasi Augmented Reality Di Museum: Studi Awal Perancangan Aplikasi Edukasi Untuk Pengunjung Museum. Konferensi Nasional Teknologi Informasi dan Komunikasi 2013, Universitas.ccYogyakarta: Universitas Kristen Duta Wacana. 